\title{
Psicopedagogia e Biologia do Amor: Reflexões sobre o Sentir, o Outro e a Solidariedade
}

\author{
Henrique Miguel de Lima Silva ${ }^{1}$, Danielli Cristina de Lima Silva², Symara Abrantes Albuquerque de Oliveira Cabral ${ }^{3}$, \\ Maria Carmem Batista de Alencar ${ }^{4}$, Edgley Gonçalves Alves Segundo ${ }^{5}$
}

\begin{abstract}
Resumo: O presente artigo propõe-se a refletir sobre a biologia do amor e suas reflexões na/para clínica psicopedagógica. Parte-se do pressuposto de que a clínica psicopedagógica, além de trabalhar com dificuldades de aprendizagem, pode, ao trabalhar com a perspectiva de Maturana (2001), contribuir para o desenvolvimento integral do sujeito enquanto ser sociohistórico e dialógico. Ressalta-se que foi utilizado a perspectiva bibliográfica para elaboração da presente pesquisa. Inicialmente, tem-se como objetivo geral o questionamento da formação do sujeito em contextos formais de ensino que, muitas vezes, desconsidera o processo sociocultural de aprendizagem humana. Pires e Silva $(2015,2016)$ propõem um olhar mais reflexivo sobre a atuação do psicopedagogo em contextos clínicos e instituições, principalmente, no que concerne as dificuldades e atuações.
\end{abstract}

Palavras-Chave: Psicopegagogia, Biologia do amor, desenvolvimento.

\section{Educational Psychology and Biology of Love: Reflections on the Feel, the Other and Solidarity}

\begin{abstract}
This article proposes to reflect on the biology of love and his reflections on / for psychoeducational clinic. This is on the assumption that the psychopedagogical clinic, in addition to working with learning difficulties can, working with the prospect of Maturana (2001), contribute to the integral development of the individual as being socio-historical and dialogical. It is noteworthy that was used the bibliographical perspective for the development of this research. Initially, it has the general objective of the questioning of the formation of the subject in formal education that often disregards the socio-cultural process of human learning. Pires and Silva $(2015,2016)$ propose a more reflective look at the role of the educational psychologist in clinical settings and institutions, mainly regarding the difficulties and performances.
\end{abstract}

Keywords: Educational Psychology, Biology of Love, development.

\section{Introdução}

O processo de aprendizagem humana é, sem dúvida, um dos processos sociocognitivos mais fascinantes e intrigantes que, por sua vez, vem sendo estudado ao longo do tempo.

\footnotetext{
${ }^{1}$ Doutorando em Linguística - Universidade Federal da Paraíba - João Pessoa - PB, Brasil. E-mail: henrique.miguel.93@ hotmail.com;

${ }^{2}$ Graduada em Psicopedagogia pela UFPB. Pesquisadora do Laboratório de Processamento Linguístico da UFPB - LABROL/CNPQ. Aluna especial do Mestrado em Linguística da UFPB. E-mail: limaanacrisdani@ gmail.com;

${ }^{3}$ Doutoranda em Ciências da Saúde - Faculdade de Ciências Médicas da Santa Casa de São Paulo. E-mail: symara_abrantes@ hotmail.com.

${ }^{4}$ Mestranda em Sistemas Agroindustriais - Universidade Federal de Campina Grande. E-mail: carmemsjp@ hotmail.com. Paraíba, Brasil;

${ }^{5}$ Graduação em Contabilidade - Faculdade de Filosofia, Ciências e Letras de Cajazeiras - PB, Brasil. E-mail: segundo_cz@ hotmail.com.
} 
No entanto, quando correlaciona-se este com os processos de aprendizagem formal, percebe-se que há uma grande lacuna entre educação formal, aprendizagem como um todo e, sobretudo, ensino. Neste sentido, de quais maneiras a clínica psicopedagógica pode contribuir para o desenvolvimento integral a partir da perspectiva da biologia do amor?

Responder este questionamento foi, sem dúvida, um dos principais motivos que fez Maturana (2001) construir todo um aparato epistêmico. De acordo com o autor é a vivência cotidiana que nos proporciona a perspectiva do entendimento do outro, de modo que o ser vivo pode ser considerado uma máquina capaz de processar e reprocessar a informação.

A partir desta perspectiva, percebe-se que a reflexão sobre a educação na biologia do amor e suas implicações no sentido de sentir o outro é falar dos sentimentos, é falar sobre a queda de mecanismos mecanicistas que estão cada vez ficados para traz e dando lugar ao conhecimento humano de maneira mais amplo.

\section{Metodologia}

Trata-se de um estudo bibliográfico, exploratório, com abordagem qualitativa dos dados a partir dos objetivos propostos. Para tanto, buscou-se a utilização de referencial teórico científico atualizado para contrapor ou interpor as reflexões de autores clássicos na abordagem ao tema.

\section{Resultados e Discussões}

De acordo com Pires e Silva (2016), pensar nos desafios contemporâneos da aprendizagem implica, necessariamente, em compreender os espaços sociais em que cada indivíduo encontra-se inserido. É preciso, dentro desse conjunto de dados possibilitar reflexões que, por sua vez, contribuam diretamente para a formação do sujeito de modo a correlacionais fatores culturais e formais, dentro dessa sociedade pós-moderna e em constante transformações. 
É justamente, a partir do momento em que questiona-se sobre a importância do conhecer para uma formação humana mais significativa e prazerosa pautada os próprios valores humanos além de sua intelectualidade, mas do seu sentir. O seu idealizador Humberto Romesin Maturana Ph.D em biologia nos permitir uma reflexão acerca do nosso olhar ser nas emoções, onde esta se torna a base para a convivência humana.

Foram os estudos de Maturana (1997, 2001, 2005) a Biologia do amor que nos permiti enquanto educadores e também futuros psicopedagogos clínicos, a termos um olhar além da formação cognitiva do nosso aprendente, mas buscarmos um olhar voltado para o todo, ou seja, o funcionamento do sistema nervoso, sua formação biológica como sua extensão ao âmbito social humano. A biologia do amar é, conforme o autor, o fundamento biológico do mover-se de um ser vivo, no prazer de estar onde está na confiança de que é acolhido, seja pelas circunstâncias, seja por outros seres vivos.

As reflexões aqui trazidas por Maturana os impulsionam a um questionamento acerca desse olhar além da cognação humana, além da decodificação de símbolos e da aquisição do conhecer por conhecer, ou ter que conhecer para cumprimento dos currículos, mas do conhecer para significar algo para a vida, para aprender e saborear; saborear o conhecer. Sim saborear o conhecimento em sua forma plena e emocional do despertar pelo desejo, pela curiosidade de ser um ser em constante desenvolvimento com ele mesmo, com o outro e com o universo, um ser que não limita-se com a descoberta do hoje, mas que questiona e deseja novas descobertas. Isso só será possível como nos afirma Maturana existir o prazer da acolhida entre os seres e na confiança estabelecida entre os mesmos.

Neste sentido, compreende-se que:

\begin{abstract}
A emoção de vida funda o social, elabora a sociedade. Somente existe sociedade como resultante das relações que se fundam na aceitação do outro como legítimo outro na convivência, na conduta de respeito. Se não há interação na aceitação mútua, produz-se a separação ou a destruição. Relações humanas que não estão fundadas na emoção de vida não são relações sociais. Nem todas as relações humanas são sociais, (...) porque nem todas se fundam na operacionalidade da aceitação mútua (MATURANA, 2005, 26).
\end{abstract}

Dentro dessa dialética, eminentemente, humana das relações sociais é que o campo das aprendizagens funciona. Todavia, um grande problema encontra-se na questão da forte relação entre educação formal e aprendizagens culturais. Uma possível saída para esta 
situação dialética em que muitas vezes os espaços de educação formal parecem descartar todo o conhecimento de mundo que o educando possui em detrimento de uma "robotização".

Para o autor:

A tarefa do âmbito escolar é criar as condições que permitam que a criança amplie sua capacidade de ação e reflexão no mundo em que vive, de modo que possa contribuir para a sua conservação e transformação de maneira responsável em coerência com a comunidade e o meio ambiente natural a que pertence. O que está em jogo neste processo é o enriquecimento da capacidade de fazer e refletir da criança, não a transformação ou mudança de seu ser (MATURANA, 2005, 14).

Faz-se necessária outra reflexão, que para se aprender devemos sentir o outro tanto com suas individualidades de ser singular e único e em suas características de personalidade, mas também ser coletivo em seus direitos enquanto pessoa que na sua construção e criação do saber acrescenta e contribuí com a minha aprendizagem tornando-a dessa maneira singular e coletiva; singular por ser minha e coletiva por ser nossa. Dessa maneira observamos que não se aprende sozinho, é um caminho que se deve fazer acompanhado, o eu aprendendo ou melhor se permitindo aprender com o outro, porque não dizendo, se inspirando no outro.

Inspirar-se em alguém nos permitirá perceber que somos resultados de aprendencias, das nossas e das aprendencias dos outros. Termos um olhar enquanto psicopedagogo clínico para além de nossas histórias e das histórias do nosso aprendente, mas fazermos uma junção do resultado de várias outras histórias que podemos então chamarmos de aprendencias. De questionamentos e perguntas, aprendencias pautadas no questionar e na formulação de perguntar transportando o aprendente a uma posição de investigação da sua própria construção saber.

Segundo Beauclair deve-se a perceber que não aprendemos sozinhos e que para tal é preciso o exercício do ato humano do indagar-se, do perguntar, nos permitindo através de Paulo Freire:

Uma Pedagogia da pergunta, um ensinar e aprender, um educar que é o ato humano de perguntar, dialogar. Entre ensinantes e aprendentes, a relação de verticalidade, onde uns são sujeitos e outros objetos, não podendo jamais existir (BEAUCLAIR, 2008,p.56).

Dessa maneira admitimos uma proposta dialógica, visto que todos nós somos sujeitos do ato de conhecer, do ato cognoscente, da partilha do saber, do conhecer, e do ser. 
Id on Line Revista Multidisciplinar e de Psicoloqia

Id on Line Multidisciplinary and Psychology Journal

Mediante esta proposta dialógica e não depositaria, que se adéqua tão em a Psicopedagogia e sua atuação, o que teríamos a refletir sobre sentimentos e inteligência. Como em um impulsionar a pensar na emoção dos sentimentos e a razão da inteligência nos reportamos a Rubens Alves,

No silêncio das crianças há um programa de vida: sonhos. É dos sonhos que nasce a inteligência. A Inteligência é a ferramenta que o corpo usa para transformar os seus sonhos em realidade. É preciso escutar as crianças para que a sua inteligência desabroche (ALVES, 2005,p. 29).

Uma compreensão da inteligência que nos permitir ir além da razão, além dessa razão falada enquanto palavra dita, mas uma razão que nos remete ao ouvir. Enquanto psicopedagogos clínicos em formação será o ouvir e ouvirem sua essência de escuta, de análise e interpretação na palavra que está além das palavras faladas, mas da palavra sentida através do olhar, ampliando dessa maneira nosso olhar clinico além da escola, um olhar do outro enquanto sujeito, enquanto ser que anseia ser ouvido, que anseia ser tocado, que anseia ser visto, não apenas como uma "dificuldade de aprendizagem", como uma cognição, mas como um ser pessoa, emoção, sentimento que precisa dialogar, sentir e ser sentido, cuidar e ser cuidado, para que sua inteligência torne-se tão confiante a ponto de torna-se realidade nesse universo que chamamos de aprendizagem.

Esse desabrochar não acontecerá apenas em relação ao aprendente que terá mais confiança em si mesmo para realizar seus sonhos, mas será um desabrochar em nossa maneira de vermos e porque não dizermos de diagnosticar e realizar as intervenções. Porque a partir do momento que lapidamos nossa cognição, essa lapidação também acontece em nosso conhecimento teórico, o psicopedagogo passa por um processo de reflexão de seu próprio modo do fazer psicopedagógico. Estaremos então a fazer uma pratica "Pseudoconstrutivista". Praticas que possam resgatar o eu, fazendo um disvelamento sobre nós mesmos, ou melhor dizendo, permitindo o aprendente resgatar-se consigo mesmo e desvelar-se sobre ele mesmo. Seriam sessões que permitiria aos envolvidos uma entrega maior de suas emoções, cabendo é claro ao psicopedagogo clinico o equilíbrio e o direcionamento das mesmas, mas sem a cobrança excessiva de uma busca da patoligização, mas por uma busca do encanto com o encantamento. 
Ao considerar os problemas de aprendizagem e sabendo da complexidade que os envolvem se faz necessário que as abordagens sejam feitas por profissionais especializados, criativos e atualizados. É da competência desses profissionais especializados determinar as diferentes causas que estão por trás desta problemática e conduzir o processo de intervenção da melhor forma objetivando amenizar essa problemática.

No caso do psicopedagogo institucional, sua atuação se dá na escola identificando os alunos com dificuldade de aprendizagem em sala de aula, cabe a este profissional fazer uma intervenção com o aluno que apresenta dificuldade de aprendizagem identificar o seu perfil e fazer um paralelo com a metodologia que o professor adota.

Já o psicopedagogo clinico vai diagnosticar, orientar, atender em tratamento e investigar os problemas emergentes nos processos de aprendizagem além de esclarecer os obstáculos que interferem na aprendizagem, favorecer o desenvolvimento de atitudes e processos de aprendizagens adequadas.

Para Fernández (2001), a intervenção psicopedagógica não se dirige ao sintoma, mas o poder para mobilizar a modalidade de aprendizagem, o sintoma cristaliza a modalidade de aprendizagem em um determinado momento, e é a partir daí que vai transformando o processo ensino aprendizagem. Cabe ao psicopedagogo orientar professores e pais sobre a forma de como podem colaborar para ajudar o aprendente a potencializar suas habilidades, uma vez que de alguma forma podem compensar suas dificuldades.

Segundo Fernandez (2001) todo sujeito tem sua modalidade de aprendizagem e os meios para construir o próprio conhecimento, e isso significa uma maneira muito pessoal para se dirigir e construir o saber. O psicopedagogo para cumprir o seu papel de profissional que atua diretamente com o processo de aprendizagem humana e que tem como objeto de estudo o ser que aprende e constrói seu conhecimento aprendendo, necessita de teorias vinculadas à prática pedagógica e que envolva o atendimento às necessidades individuais de aprendizagem, o fracasso escolar e a apropriação do conhecimento, as estratégias adotadas por este profissional necessitam envolver o aprendente de forma prazerosa afim de que ele possa se sentir amado e acolhido levando em consideração os sofrimentos vividos no processo de aprendizagem, uma vez que as dificuldades de aprendizagem afetam a pessoa na sua totalidade. 
Diante da realidade da sala de aula, com alunos que mesmo com as capacidades necessárias, não conseguem atingir o rendimento que se espera deles, não aprendem como os demais, os métodos utilizados não funcionam, o desafio está lançado para o profissional da psicopedagogia que necessita estimular essas capacidades dos alunos para que eles possam produzir a si próprios. É importante acrescentar que:

\begin{abstract}
Necessitamos de um modo de pensar mais complexo, mais profundo e abrangente que reconheça o mundo fenomenal constituído de totalidade/partes e que não fracione o ser humano nem separe o indivíduo do mundo em que vive. Um pensar complexo que compreenda que razão, emoção, sentimento e intuição são elementos inseparáveis, que reconheça que para pensar bem é preciso ter uma compreensão mais clara a respeito da dinâmica da realidade e dos processos nos quais estamos envolvidos. Necessitamos de um olhar mais profundo sobre a realidade para que possamos retomar o diálogo esquecido com a natureza que já não pode continuar sendo aprisionada pelo golpe certeiro da ciência (MORAES, 2004, p.120).
\end{abstract}

Ao compreender a realidade complexa dos espaços formais de ensino, espera-se que todos os profissionais envolvidos sejam capazes a trabalhar de forma interdisciplinar, bem como que ofereça uma formação integral, em consonância com os documentos oficiais (BRASIL, 1996), bem como que esteja correlacionada com as teorias psicopedagógicas.

Inspirado pela teoria autopoiético de Maturana (2004) o Psicopedagogo precisa adotar métodos que envolva a ação/reflexão incluindo a dimensão que envolva o coração, pois para Maturana educar para o sentir pensar, é educar no caminho do amor, da inteireza e sabedoria, nesse sentido esse profissional deve priorizar a formação do Ser dando uma maior atenção ao fazer, sempre está atento para corrigir o fazer e não o Ser, favorecendo a autonomia, criatividade e criticidade para o desenvolvimento de um Ser empoderado e com a sua autoestima elevada.

O Psicopedagogo Autopoiético precisa ter uma preocupação toda especial com o ambiente em que ele vai receber o aprendente uma vez que este profissional tem a responsabilidade em estimular o desenvolvimento das potencialidades do aprendente e segundo Maturana se faz necessário trabalhar as emoções já que para ele o amor é o foco principal da aprendizagem e oferecendo um meio desorganizado não estaremos favorecendo o biológico e consequentemente o avanço do aprendente pode ficar comprometido, ao compreender que: 


\begin{abstract}
É a emoção a partir da qual se faz ou se recebe um certo fazer que o transforma numa outra ação, ou que o qualifica como um comportamento dessa ou daquela classe. Nós humanos existimos na linguagem, e todo o ser e todos os afazeres humanos ocorrem, portanto, no conversar - resultado do entrelaçamento do emocionar com o linguajar. A existência humana faz com que qualquer ocupação humana aconteça como uma rede específica de conversações. Esta é definida em sua especificidade pelo emocionar, que por sua vez define as ações que nela se coordenam (MATURANA, 2004, p. 22).
\end{abstract}

$\mathrm{Na}$ psicopedagogia é vital oferecer estratégias para a busca da valorização das possibilidades do ser que aprende, de forma a facilitar o caminho para a auto estima que se constitui no ponto chave do desenvolvimento do pensamento a partir da tomada de consciência da crença em sim mesmo e consolidação de um objeto permanente. Isso possibilita um ser mais afetivo, com formação de vínculos e como consequência mais motivação para a busca do saber.

Assim o psicopedagogo autopoiético necessita buscar estratégias a partir das habilidades apresentadas pelo aprendente, considerando que somos um reflexo do meio e que precisamos ser tolerante com o outro aceitando que cada um tem o seu tempo e que a hora quem determina é o aprendente, promovendo possibilidades para propiciar uma melhoria na qualidade dos processos de ensino-aprendizagem e oferecer uma preparação para que possa continuar sozinho.

Maturama (2001) parte do princípio de que a vida é um processo continuo de conhecimento. A consequência disso é que se tornarmos como objetivo compreende-la, será necessário entendermos como conhecemos e o que conhecemos. Nesta perspectiva necessariamente teremos que nos remeter a experiência cotidiana, ao fenômeno do conhecer. Essa atitude, em princípio nos leva a três consequências que se põem em movimento ininterrupto: olhar, explicar, agir.

Com efeito, se fazemos parte do mundo, vale dizer, da vida, é plausível nos colocarmos no posto de observadores e com a nossa experiência sensível propormo-nos a explicar o mundo tal qual o conhecemos, o que nos leva a um agir conforme experiências e representamos esse mundo. Seguindo a sua trajetória desenvolver a nossa história biológica, Maturana (2005) afirma que enquanto seres vivos, somos solitários no primeiro ato de conhecer. Solidão que só é transcendida no mundo que criamos junto com ele. É a partir dessa criação que nos fazemos no mundo através do fenômeno da "autopoiese". Autopoiese 
Id on Line Revista Multidisciplinar e de Psicoloqia

Id on Line Multidisciplinary and Psychology Journal

(autoprodução), portanto, usado para definir seres vivos como sistemas que se autoproduzem de modo ininterrupto.

É indispensável, porém, acrescentar que para que os seres vivos exerçam a autopoiese precisam necessariamente, recorrer aos recursos do meio ambiente tornando-se desta forma autônomos e independentes. Para Maturana (2001), só quando procuramos compreender o caráter sistêmico da célula é que conseguimos entender adequadamente os organismos e suas consequências. Esse movimento é que constitui o que chamamos de Biologia da cognição.

Neste sentido, explicam o fenômeno do conhecer tornando a universalidade do fazer no conhecer e submetendo o seu objeto aos critérios formais de validade científica: descrição do fenômeno, proposição de um sistema conceitual explicativo do fenômeno, dedução, a partir de b, de outros fenômenos associados ao seu fenômeno e, observação desses outros fenômenos deduzidos a partir do b.

\section{Considerações Finais}

Compreender a dinâmica da aprendizagem implica, antes de tudo, em conceber o ser humano em sua totalidade. Todavia, a escola tem sido falha por não considerar estas questões durante a socialização de conhecimento.

A Biologia do amor de surge como uma alternativa crítico-reflexiva de se considerar as potencialidades do sujeito a partir das relações entre componentes biológicos e emocionais dentro de um espaço sociocultural. Pensar dessa forma possibilita novos olhares para o processo de aprendizagem e, por conseguinte, de desenvolvimento humano.

Diante de tudo o que expomos, nos parece claro que Maturana nos mostra que vida e realidade estão, as duas, irremediavelmente juntas num processo de conhecimento continuo. Assim, a história que descortina a realidade da vida biológica e social na terra, não é outra senão a síntese de uma configuração dinâmica de fenômenos que são biológicos e sociais a um só tempo.

Sendo assim, compreender o movimento da vida dos seres vivos e desvendar a ontogenia e a fílogenia dos seres humanos em busca da formação da sua autoconsciência, que se expressa nos atos cognitivos, é compreender como se revela a essência dos seres humanos 
Id on Line Revista Multidisciplinar e de Psicoloqia

Id on Line Multidisciplinary and Psychology Journal

e sua criação, vencendo, a cada momento, a visão de aparência e de certeza que resulta do representacionismo e do positivismo que dominam, contraditoriamente, a nossa consciência do mundo.

Há, dessa maneira, uma relação de determinação no movimento da autopoiese social dos seres humanos apresentada o tempo todo como uma tensão dialética entre o ser e o seu meio. A realidade social, assim como a realidade biológica, é essencialmente contradição, síntese, antítese, nova síntese e assim por diante. Enfim, movimento contradição, mudança e unidade constante é o que há na realidade biológica e na realidade social.

\section{Referências}

ALVES, Rubens. Educação dos sentidos e mais...Campinas: Verus Editora, 2005

BEAUCLAIR, João. Ensinar é aprender. Rio de Janeiro „Editora Wak, 2008.

FREIRE, Paulo. Pedagogia do Oprimido. Rio de Janeiro: Paz e Terra, 1983

MATURANA, Humberto. Cognição, Ciência e Vida Cotidiana. Belo Horizonte: Editora Universidade de Minas Gerais. 2001

2005

Emoções e linguagem na educação e na política. Belo Horizonte: Editora UFMG.

Humberto Maturana: Entrevista. Humanitates v.1 n.2 nov/2004. Disponível em http://www.humanitates.ucb.br/2/entrevista.htm > Acesso em 25jul2016

MORAES, Maria Cândida. Pensamento eco-sistêmico: educação, aprendizagem e cidadania no século XXI. Petrópolis: Vozes, 2004.

PIRES, Thereza Sophia Jácome; SILVA, Henrique Miguel de Lima. A Escrita do Surdo como Prática de Educação Inclusiva na Educação Básica. In: PALITOT, M. D.; A Transversalização de temas Educacionais e Sociais no Desenvolvimento das Escolas Brasileirasr. João Pessoa. Ideia: 2015.

PIRES, Thereza Sophia Jácome; SILVA, Henrique Miguel de Lima. Os Desafios da Psicopedagogia Clínica e Institucional na Pós-Modernidade. In: PALITOT, M. D.; SEABRA, M. A. B; PIRES, T. S. J; SILVA, H. M. L. Caminhos e Reflexões Psicopedagógicas e Interdisciplinares para Aprender a Aprender. João Pessoa. Ideia: 2016. 
VARELA, Francisco (1992). Prefacio de Francisco J. Garcia Varela à segunda edição. In Maturana, Humberto e VARELA, Franscisco (1992). De máquinas e seres vivos. Autopoiese: a organização do ser vivo. Artes Médicas: Porto Alegr, 1997.

\section{Como citar este artigo (Formato ABNT):}

SILVA, H.M.L.; SILVA, D.C.L.; CABRAL, S.A.A.O.; ALENCAR, M.C.B.; SEGUNDO, E.G.A. Psicopedagogia e Biologia do Amor: Reflexões sobre o Sentir, o Outro e a Solidariedade. Id on Line Revista Multidisciplinar e de Psicologia, Out-Nov. de 2016, vol.10, n.31, Supl 3, p. 21-31. ISSN 1981-1179.

Recebido: 24/10/2016

Aceito: $26 / 10 / 2016$ 